\title{
General Anesthesia with Laryngeal Mask Airway: Etomidate vs Propofol for Hemodynamic Stability
}

\author{
Hashaam B. Ghafoor, Gauhar Afshan, Rehana Kamal \\ Department of Anaesthesia, Aga Khan University, Karachi, Pakistan. \\ Email: drhashaamghafoor@hotmail.com,gauhar.afshan@aku.edu,rehana.kamal@aku.edu
}

Received July $4^{\text {th }}, 2012$; revised August $5^{\text {th }}, 2012$; accepted August $28^{\text {th }}, 2012$

\begin{abstract}
Background: Propofol is the most popular induction agent for laryngeal mask airway (LMA) insertion in current anaesthesia practice however associated hypotension has been reported as its major disadvantage. Etomidate, which produces less hypotension, can be considered as an alternative agent for LMA insertion. Objectives: The objective of this study was to compare the hemodynamic effects of etomidate with propofol for induction of general anaesthesia (GA) for LMA. Ease of inserting LMA was also looked at. Material and Methods: It was a prospective randomized double blinded study. All ASA I and II patients of 15 - 60 years of age undergoing general anaesthesia with LMA for elective surgeries were included. Patients were induced with intravenous $(\mathrm{I} / \mathrm{V})$ fentanyl and induction agent either etomidate or propofol according to group randomization. LMA was inserted after 30 seconds. Intra-operative heart rate (HR), systolic blood pressure (SBP), diastolic blood pressure (DBP), mean arterial pressure (MAP), number of attempts and duration of LMA insertion were monitored. Results: There was no difference in the heart rate between the two groups. A significant drop was found for systolic blood pressure (SBP) in propofol group while diastolic blood pressure (DBP) was decreased in both the groups. In propofol group, successful in-sertion of LMA was achieved on the first attempt in 93.3\% of patient as compared to $36.7 \%$ in etomidate group. Conclusion: Use of etomidate for induction of laryngeal mask anesthesia can prevent the hypotension following induction; however it may delay the insertion of laryngeal mask airway.
\end{abstract}

Keywords: Propofol; Etomidate; Hemodynamic Effects; Laryngeal Mask Airway

\section{Introduction}

LMA has gained the wide acceptability for securing the airway in patients undergoing elective surgery under general anaesthesia (GA). Propofol is the most popular induction agent for LMA insertion in current anaesthesia practice however its cardiovascular side effects, especially hypotension, has been questioned its routine use for LMA insertion in high risk cardiovascular patients [1]. Etomidate produces less cardiovascular depression than other commonly used induction agents like thiopentone $\mathrm{Na}$ and propofol. It is considered the induction agent of choice for high-risk patients with cardio respiratory diseases and for that reason it has also been used for LMA insertion $[2,3]$.

Smooth insertion of LMA requires adequate mouth opening and suppressed airway reflexes. Etomidate although maintains the better hemodynamic, does not depress the upper airway reflexes and may cause difficulties in the insertion of LMA. Concurrent use of fentanyl, remifentanil and succinylcholine had been found effective to improve conditions for LMA insertion with etomidate
$[3,4]$. Nevertheless current literature lacks randomized controlled trial for induction agent of choice for LMA insertion. We hypothesized that etomidate with concurrent use of fentanyl could prevent the hypotension following induction of GA for LMA insertion. In this study we compared etomidate with propofol for hemodynamic effects and ease of insertion of LMA at induction of GA.

\section{Material and Methods}

After approval of Ethical Review Committee and written informed consent, we enrolled 60 patients into this prospective, randomized, double blinded study. This sample size was required to obtain a power of $80 \%$ and the probability of type I $(\alpha)$ error equal to 0.05 to detect the difference in the hemodynamic parameters following induction.

All ASA I or II, aged between 15 - 60 years, scheduled for elective surgeries requiring GA with LMA were eligible for our study. Patients with history of epilepsy/ seizure disorder, hypertension, gastro esophageal reflux disease, allergy/hypersensitivity to propofol and etomi- 
date, patients taking beta blockers and difficult LMA insertion requiring more than 40 seconds were excluded.

The convenience sampling was used for enrolment in this study. Patients were then randomly allocated to groups " $A$ " and "B" using sealed envelope to receive either etomidate or propofol respectively for induction of anesthesia. For blinding purpose primary anesthesiologist was responsible for patient randomization and induction of general anesthesia while other investigator (unaware of group allocation) was responsible for data collection. For the purpose of double blinding, patients were also kept unaware of group allocation. All patients were fasted for over $6 \mathrm{~h}$ and routine premedication was given.

Etomidate is a white color solution available in $10 \mathrm{ml}$ ampoule in concentration of $2 \mathrm{mg} / \mathrm{ml}$. It was diluted with water in 1:1 ratio and total volume was made $20 \mathrm{mg}$ in $20 \mathrm{ml}$ syringe with final concentration of $1 \mathrm{mg} / \mathrm{ml}$. Propofol is available in $20 \mathrm{ml}$ vial in concentration of $10 \mathrm{mg} /$ $\mathrm{ml}$. Propofol was also filled in $20 \mathrm{ml}$ syringe for blinding purpose.

In the operating room standard monitoring i.e. heart rate (HR), systolic blood pressure (SBP), diastolic blood pressure (DBP) and mean blood pressure (MAP) were applied and baseline readings were recorded. All patients were pre oxygenated for 3 minutes with oxygen flow rate of $6 \mathrm{~L} / \mathrm{min}$ on circle breathing system. Patients were induced with intravenous (I/V) fentanyl $2 \mathrm{mcg} / \mathrm{kg}$ and induction agent either etomidate or propofol according to randomization. Group "A" received I/ $\mathrm{V} 0.3 \mathrm{ml} / \mathrm{kg}$ of etomidate $(0.3 \mathrm{mg} / \mathrm{kg})$ while group "B" received $\mathrm{I} / \mathrm{V}$ propofol $0.3 \mathrm{ml} / \mathrm{kg}(3 \mathrm{mg} / \mathrm{kg})$ over $30 \mathrm{sec}$. LMA size 3 for female and size 4 for male was inserted 30 seconds after the induction agent given. Maintenance of anaesthesia was achieved with oxygen $\left(\mathrm{O}_{2}\right)$, nitrous oxide $\left(\mathrm{N}_{2} \mathrm{O}\right)$ in $1: 2$ ratio and sevoflurane $2 \%-3 \%$ with spontaneous ventilation on circle breathing system.

The hemodynamic parameter including HR, SBP, DBP and MAP were measured at baseline, before administration of induction agent and then every minute (min) until 10 min after induction. Number of attempts and total duration of LMA insertion were also recorded.

\section{Statistical Analysis}

Statistical package for social sciences "SPSS-16.0" was used for analysis. The continuous response variables like age, weight, height, BMI, duration of LMA insertion, number of attempts, were presented by Mean \pm SD and $t$-test was applied to compare the means between propofol and etomidate group. Hemodynamic responses (HR, SBP, DBP and MAP) were analyzed by repeated measure ANOVA, while categorical data were analyzed by Chi square test. p-value $<0.05$ was considered significant.

\section{Results}

A total of 60 patients were entered in this study. In etomidate group, male to female ratio was $26: 4$ while in propofol was 15:15. This gender distribution was statisticcally significant $(p<0.002)$. The mean age and weight of patients between the groups was statistically insignificant (Table 1).

No statistically significant difference was found in the heart rate between the two groups at all study timings (Figure 1).

There was a statistically significant $(p<0.013)$ drop of SBP in the propofol group at all study timings when compared with etomidate group (Figure 2).

Table 1. Comparison of demographic and procedural features between two groups.

\begin{tabular}{lccc}
\hline \multicolumn{1}{c}{ Variables } & $\begin{array}{c}\text { Etomidate } \\
(\mathbf{n}=\mathbf{3 0})\end{array}$ & $\begin{array}{c}\text { Propofol } \\
(\mathbf{n}=\mathbf{5 0})\end{array}$ & p-value \\
\hline $\begin{array}{l}\text { Gender } \\
\text { (male/female) }\end{array}$ & $26: 3$ & $15: 15$ & 0.002 \\
& & & \\
Age (years) & $45.4 \pm 13.1$ & $42.9 \pm 12.7$ & 0.462 \\
& & & \\
Weight (kg) & $69.7 \pm 12.7$ & $69.9 \pm 12.4$ & 0.943 \\
& & & \\
$\begin{array}{l}\text { Duration of insertion } \\
\text { of LMA (seconds) }\end{array}$ & $38.23 \pm 2.1$ & $36.43 \pm 3.07$ & \\
& & & \\
& & & \\
$\begin{array}{l}\text { No of attempts for } \\
\text { insertion of LMA }\end{array}$ & $11(36.7 \%)$ & $28(93.3 \%)$ & \\
$\begin{array}{l}\text { 1. attempt } \\
\text { 2. attempts }\end{array}$ & $19(63.3 \%)$ & $2(6.7 \%)$ & \\
\hline
\end{tabular}

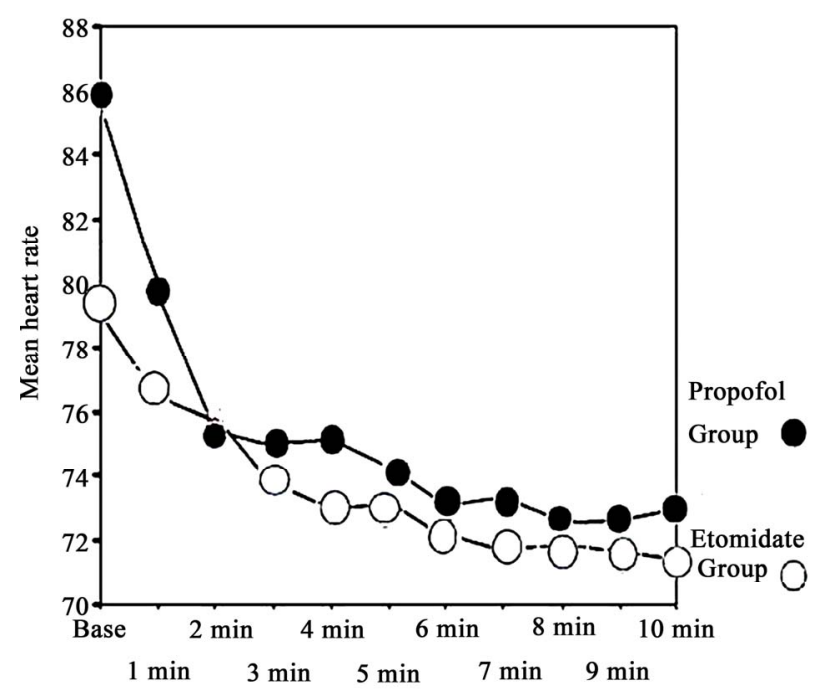

Figure 1. Comparison of heart rate between etomidate and propofol groups. 
For the DBP both the groups were very well matched at all study timings with significant difference within subjects from base line reading to the endpoint of the study (Figure 3).

There was a transient fall of MAP in both the groups and difference was statistically significant $(p<0.001)$ however it was more profound in propofol group than etomidate group (Figure 4).

The successful insertion of LMA at first attempt was found in $93.3 \%$ of patients in propofol group while $36.7 \%$ in the etomidate group with significant statistical difference $(p<0.001)$. The mean time required for LMA insertion was found more in etomidate group than propofol $(38.23 \pm 2.1$ vs. $36.43 \pm 3.07, \mathrm{p}<0.010)$ as shown in Table 1.

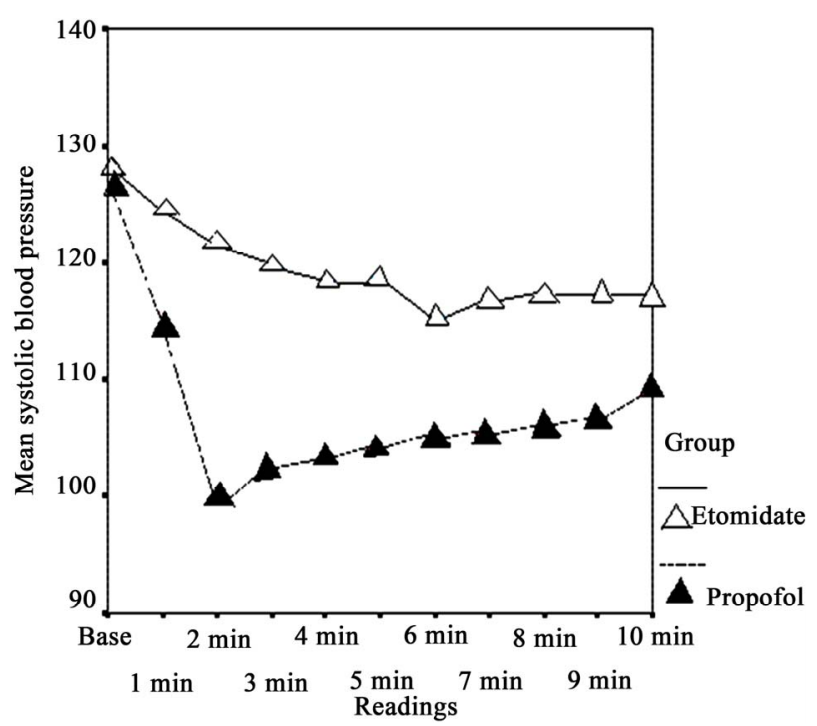

Figure 2. Comparison of systolic blood pressure between etomidate and propofol groups.

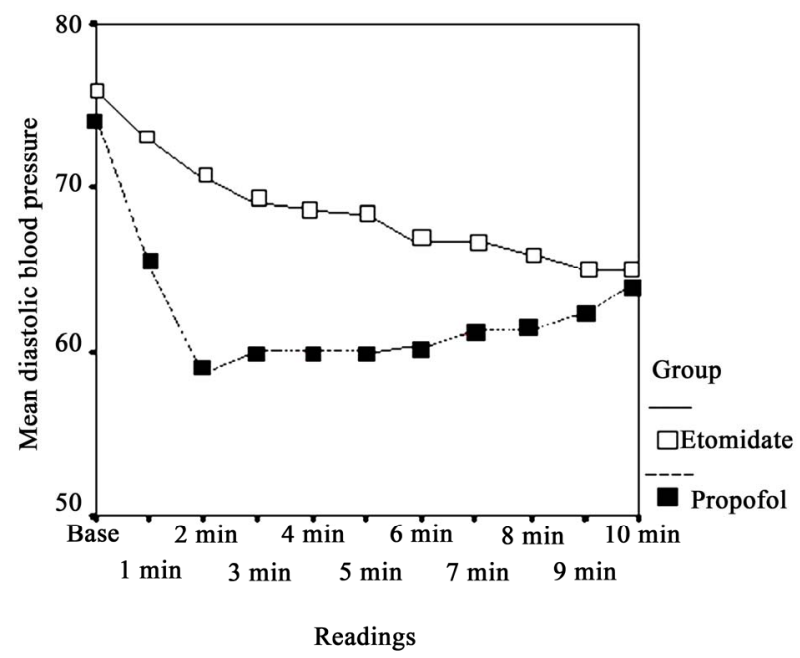

Figure 3. Comparison of diastolic blood pressure between etomidate and propofol groups.

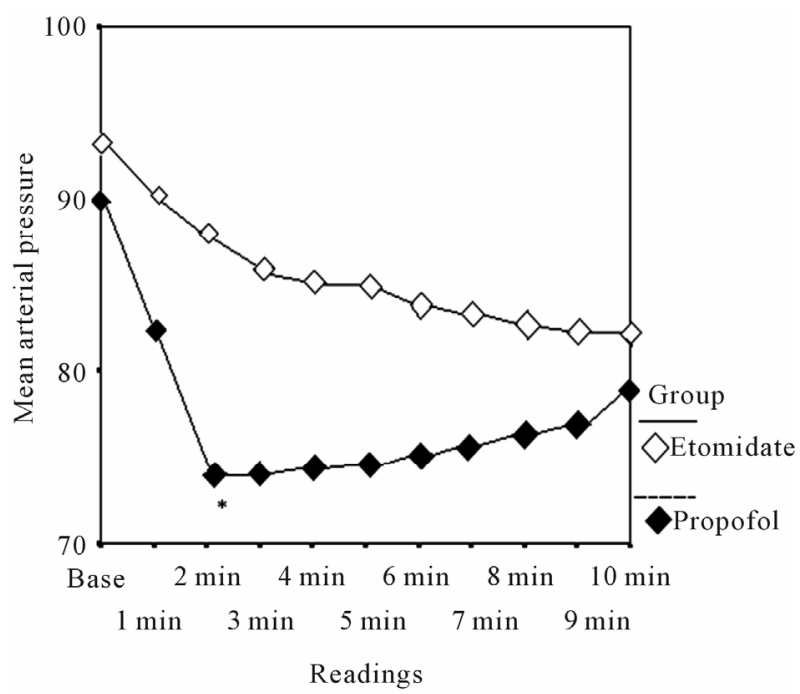

Figure 4. Comparison of diastolic blood pressure between etomidate and propofol groups.

\section{Discussion}

LMA has been in anaesthesia practice for the last 25 years. Smooth and successful insertion of LMA requires adequate mouth opening with suppressed upper airway reflexes to avoid gagging, coughing and laryngospasm. Despite the popularity of LMA for general anaesthesia, the optimal induction agent that guarantees good insertion conditions while maintaining cardiovascular stability has not been found. To date most anesthesiologists use propofol for LMA anaesthesia, as this agent best obtunds upper airway or oropharyngeal reflexes [5].

The induction dose of propofol $(2-3 \mathrm{mg} / \mathrm{kg})$, which allow jaw relaxation and prevent patient reaction to LMA insertion like movement and laryngospasm, usually results in hypotension [6,7]. However the standard induction dose of propofol does not guarantee optimal insertion conditions as $38 \%$ to $60 \%$ of patient have shown poor insertion conditions in the previous literature leading to additional doses of propofol causing more hypotension [810].

The numerous methods have been used to prevent hypotension associated with propofol like prophylactic ephedrine [11], preloading [12], prophylactic metaraminol [13] and ketamine-propofol mixture [1]. All these methods are not devoid of adverse affects. This study was an attempt to find the optimal induction agent for LMA insertion which can preserve hemodynamic stability. We compared propofol with etomidate for hemodynamic stability during LMA anesthesia. In existing literature with best of our search we did not find any randomized control trail comparing propofol with etomidate for LMA anaesthesia.

In our study we found significant difference for gender distribution between the groups. This finding can be ig- 
nored as previous literature regards pharmacokinetics of both induction agents did not support any gender associated hemodynamic response. In our study mean heart rate changes were comparable in both the groups with no significant difference. Literature lacks such comparison for heart rate with etomidate and propofol. However in a previously randomized, double-blinded study the authors investigated the effect of adding remifentanil to etomidate for heart rate and found prevention of tachycardia related to the insertion of the LMA [14]. In our country remifentanil was not available so we used fentanyl and found this equally effective in prevention of tachycardia in both the groups. Cheng in his study however could not prevent tachycardia associated with LMA insertion with fentanyl. This could be due to its low dose of fentanyl i.e. $1 \mathrm{mcg} / \mathrm{kg}[15]$.

In recent past, there are very few studies conducted to compare the hemodynamic stability of etomidate with propofol (alone) for LMA insertion. Aziz et al. found significant drop of SBP from the baseline after one minute in propofol group similar to our results. Our study results for DBP and MAP were also well match with the previous study conducted by Aziz [16].

Although hypotension after induction of anaesthesia with propofol has been well documented but degree of hypotension reported varies between the studies. In our study trend of transient fall of MAP in both groups was noticeable however, statistically it was more pronounced in propofol group. These results are similar with study conducted by Price M. L. et al. [17].

Propofol is known to have a relaxant effect on jaw muscles but sometime even a dose of $3 \mathrm{mg} / \mathrm{kg}$ alone does not completely control the response to LMA insertion and addition of narcotics such as fentanyl is recommended to obtund responses to LMA insertion [18]. Brown et al. reported that $2.5 \mathrm{mg} / \mathrm{kg}$ propofol combined with $1 \mu \mathrm{g} / \mathrm{kg}$ fentanyl had a favorable effect on responses to LMA insertion [19]. In our study we also used fentanyl along with propofol that allowed LMA insertion in first attempt in majority of patients.

Etomidate, as a sole induction agent, does not provide adequate jaw relaxation for the insertion of LMA. In a study by Christine J. C. Cheng et al., fentanyl $1 \mu \mathrm{g} / \mathrm{kg}$ has been added with etomidate $0.3 \mathrm{mg} / \mathrm{kg}$ and found this combination was successful in $20 \%$ of patients for LMA insertion, although number of attempts was not mentioned in remaining $80 \%$ of the patients [15]. Our results are little better than previous report and could be because of the dose of fentanyl $2 \mathrm{mcg} / \mathrm{kg}$. A study by Liou et al. also supported our results as they found LMA insertion was far better with reduce airway reflexes when etomidate was used in combination with fentanyl $2 \mu \mathrm{g} / \mathrm{kg}$ as compared with etomidate alone [3].

Our study has some strength and few weaknesses. In our opinion double blind technique, random allocation, well defined inclusion and exclusion criteria and data collection are the strengths of the study. Non availability of equipotent doses of propofol and etomidate for successful insertion of LMA in 30 seconds is one of the weaknesses of our study. Propofol in a dose of $3 \mathrm{mg} / \mathrm{kg}$ used in our study may be responsible for fall in BP. However, this dose of propofol was not excessively large for the young patients which we studied. Our study was conducted in young ASA I and II patients which will truly will not reflect for old age patient with relatively unstable hemodynamic. However this study may be a foundation stone to affix the appropriate dose and establish universal guidelines in order to find induction agent of choice for LMA to minimize anaesthesia related morbidities.

\section{Conclusion}

We conclude that the use of etomidate for induction of laryngeal mask anesthesia can prevent hypotension following induction; however it may delay the insertion of laryngeal mask airway even if it is used with narcotic like fentanyl. This study has raised another pertinent question i.e. the incidence of hypotension between the equipotent dosages of etomidate and propofol (which we did not plan in our study) required for successful insertion of LMA in 30 seconds.

\section{REFERENCES}

[1] P. K. Goh, C. L. Chi, C. Y. Wang, Y. K. Chans and P. L. Loo, "Randomized Double Blind Comparison of Ketamine-Propofol, Fentanyl-Propofol and Propofol-Saline on Hemodrnamics and Laryngeal Mask Airway Insertion Conditions," Anaesthesia and Intensive Care, Vol. 33, No. 2, 2005, pp. 223-228.

[2] J. W. Chiu and P. F. White, "Non-Opioid Intravenous Anaesthesia: Clinical Anesthesia," Lippincott Williams and Wilkins, Philadelphia, 2001.

[3] C. M. Liou, W. T. Hung, C. C. Chen and S. C. Hsu, "Improving the Success Rate of Laryngeal Mask Airway Insertion during Etomidate Induction by Using Fentanyl or Succinylcholine," Acta Anaesthesiology Taiwan, Vol. 42, No. 4, 2004, pp. 209-213.

[4] S. Uzun, A. Gozacan, O. Canbay and S. Ozgen, "Remifentanil and Etomidate for Laryngeal Mask Airway Insertion," Journal of International Medical Research, Vol. 35, No. 6, 2007, pp. 878-885.

[5] P. Scanlon, M. Carey and M. Power, "Patent Response to Laryngeal Mask Insertion after Induction of Anaesthesia with Propofol or Thiopentone," Canadian Journal of Anesthesia, Vol. 40, No. 9, 1993, pp. 816-818. doi:10.1007/BF03009250

[6] S. Hickey, A. E. Cameron and A. J. Ashbury, "Cardiovascular Response to Insertion of Brain's Laryngeal Mask," Anaesthesia, Vol. 45, No. 8, 1990, pp. 629-633. 
[7] D. W. Blake, P. Dawson, G. Donnan and A. Bjorksten, "Propofol Induction for Laryngeal Mask Insertion: Dose Requirement and Cardiorespiratory Effects," Anaesthesia and Intensive Care, Vol. 20, No. 4, 1992, pp. 479-483.

[8] S. Ang, K. F. Cheong and T. I. Ng, "Alfentanil Co-Induction for Laryngeal Mask Insertion," Anaesthesia and Intensive Care, Vol. 27, No. 2, 1999, pp. 175-178.

[9] P. T. Chui and E. W. Cheam, "The Use of Low-Dose Mivacurium to Facilitate Insertion of the Laryngeal Mask Airway," Anaesthesia, Vol. 53, No. 5, 1998, pp. 491-495. doi:10.1046/j.1365-2044.1998.00321.x

[10] M. D. Stoneham, S. E. Bree and J. R. Sneyd, "Facilitation of Laryngeal Mask Insertion. Effects of Lignocaine Given Intravenously before Induction with Propofol," Anaesthesia, Vol. 50, No. 5, 1995, pp. 464-466. doi:10.1111/j.1365-2044.1995.tb06007.x

[11] F. Gamlin, J. Freeman, L. Winslow, J. Berridge and M. Vucevic, "The Haemodynamic Effects of Propofol in Combination with Ephedrine in Elderly Patients (ASA Groups 3 and 4)," Anaesthesia and Intensive Care, Vol. 27, No. 5, 1999, pp. 477-480.

[12] R. J. Turner, S. P. Gatt, P. C. A. Kam, I. Ramzan and M. Daley, "Administration of a Crystalloid Fluid Preload Does Not Prevent the Decrease in Arterial Blood Pressure after Induction of Anaesthesia with Propofol and Fentanyl," British Journal of Anaesthesia, Vol. 80, No. 6, 1998, pp. 737-741. doi:10.1093/bja/80.6.737

[13] C. L. Chiu, G. P. Tew and C. Y. Wang, "The Effect of Prophylactic Metaraminol on Systemic Hypotension Caused by Induction of Anaesthesia with Propofol in Patients over 55 Years Old," Anaesthesia, Vol. 56, No. 9, 2001, pp. 893-897. doi:10.1046/j.1365-2044.2001.02059-4.x

[14] M. P. Lee, J. S. Kua and W. K. Chiu, "The Use of Remifentanil to Facilitate the Insertion of the Laryngeal Mask Airway," Anesthesia \& Analgesia, Vol. 93, No. 2, 2001, pp. 359-362.

[15] J. C. Cheng, S. Raman, T. J. Ridgway and C. P. Chia, "Use of Low-Dose Suxamethonium to Facilitate Laryngeal Mask Insertion under Etomidate Anaesthesia," The Internet Journal of Anesthesiology, Vol. 6, No. 2, 2003, p. 80.

[16] A. Leena and B. Khalid, "Comparison of Armored Laryngeal Mask Airway with Endotracheal Tube for Adenotonsillectomy," Java PSP Emulator, Vol. 16, No. 11, 2006, pp. 685-688.

[17] M. L. Price, B. Millar, M. Grounds and J. Cashman, "Changes in Cardiac Index and Estimated Sysemic Vascular Resisance during Induction of Anaesthesia with Thiopentone, Methohexitone, Propofol and Etomidate," British Journal of Anaesthesia, Vol. 69, No. 2, 1992, pp. 172-176. doi:10.1093/bja/69.2.172

[18] M. Kanazawa, M. Nitta, T. Murata and T. Suzuki, "Increased Dosage of Propofol in Anesthesia Induction Cannot Control the Patient's Responses to Insertion of a Laryngeal Mask Airway," Tokai Journal of Experimental and Clinical Medicine, Vol. 31, No. 1, 2006, pp. 35-38.

[19] G. W. Brown, N. Patel and F. R. Ellis, "Comparison of Propofol and Thiopentone for Laryngeal Mask Insertion," Anaesthesia, Vol. 46, No. 9, 1991, pp. 771-772. doi:10.1111/j.1365-2044.1991.tb09776.x 